\title{
Open in art, nature and emergence
}

\author{
Jennifer Seevinck \\ Creativity and Cognition Studios \\ University of Technology Sydney, Haymarket, \\ Sydney 2000 Australia \\ jenseevinck@smArtnoise.net
}

\begin{abstract}
The interactive art system +-now is modelled on the openness of the natural world. Emergent shapes constitute a novel method for facilitating this openness. With the art system as an example, the relationship between openness and emergence is discussed. Lastly, artist reflections from the creation of the work are presented. These describe the nature of open systems and how they may be created.
\end{abstract}

\section{Author Keywords}

Open, emergence, emergent shape, nature, design, exploration, reflection, interactive art, sand, tangible user interface.

\section{ACM Classification Keywords}

H.5.1 [Information Interfaces and Presentation]: Multimedia Information Systems--- Artificial, augmented and virtual realities; H.5.2 [Information Interfaces and Presentation]: User Interfaces---Haptic I/O, Input Devices and Strategies, Interaction styles. J.5 [Arts and Humanities]: Fine Arts.

\section{INTRODUCTION}

This paper begins with a brief theoretical discussion of openness and interaction. The art system +-now (plus minus now) by the first author is then described. This is an artwork that was inspired by a natural landscape. The conceptual process led to an appreciation of openness and the understanding that it is a ubiquitous, natural quality. Creating an open art system became an objective. It was addressed by creating the potential for emergence within the art system. The paper discusses the relationship between openness and emergence. Practitioner reflections on the characteristics of open systems such as creativity and unpredictability are then described, along with examples from the design methods used in +-now.

\section{OPENNESS}

Umberto Eco's 1962 description of the open 'work in movement' is applicable to contemporary interaction design: ambiguous with a large range of possible interpretations, performances or completions, it invites the participant or performer to "make the work together with the author" (Eco 1962). Here the participant acts creatively to complete the work. In this sense they can be seen to collaborate with the designer or artist. The

OZCHI 2009, November 23-27, 2009, Melbourne, Australia. Copyright the author(s) and CHISIG

Additional copies are available at the ACM Digital Library (http://portal.acm.org/dl.cfm) or ordered from the CHISIG secretary (secretary@chisig.org)

OZCHI 2009 Proceedings ISBN: 978-1-60558-854-4

\section{Ernest Edmonds}

Creativity and Cognition Studios

University of Technology Sydney, Haymarket, Sydney 2000 Australia ernest@ernestedmonds.com

conclusion is one of many possible outcomes. As such the open work can be described as inexhaustible and unpredictable. For example the performance of Stockhausen's Klavierstuck XI where the pianist chooses between groups of notes written on a sheet of paper to determine the order in which they are played. Openness is also seen as a function of multiple interpretations by Sengers et al. (2006) and Juul (2007), where different meanings or uses of a design or computer game can be interpreted.

\section{Openness and Interaction}

This paper understands an open interaction system as one which is ambiguous and can be interpreted in multiple ways. Each interpretation is one of many possible interpretations. Such a work is unfinished until it is interpreted; i.e. a participant or collaborator is required to conclude or 'close' the work; and many conclusions are possible. As such it is also inexhaustible.

\section{DESCRIPTION OF ART SYSTEM}

\section{Visual and technical description}

$+-n o w$ is an interactive art system installed at Beta_space in the Sydney Powerhouse Museum in 2008 (Seevinck 2008). The work uses sand as an interface to interact with two images. One image is monochromatic and projected on a wall screen while the other colourful image is projected directly onto fine, white sand. The sand surface can be described as a tangible user interface (Ishii et al. 1997); while the use of real-time, virtual imagery on the sand further defines it as an augmented reality display (Azuma 1997). Gestures in the sand result in imagery projected on the sand and the rear-projected screen (see figures $1,2,4,5)$. The wall imagery behaves like visual echoes, mimicking the shape, direction and speed of a mark in the sand with repeated renderings. It is described as facilitating “...layering and moving across time. Visual echoes of gestures on the large screen add up in opacity to create areas of increased brightness, enabling the interpretation of new shapes. At the same time the image persists and one can interact with a history of one's gestures. The work addresses these aspects while encouraging the participant to be present in the moment, in the now" (Seevinck 2008).

\section{Openness as a design objective}

+-now is inspired by a natural landscape with a large pond. During an initial site analysis the artist studied land and water features and interpreted the place as encouraging a highly involved, 'lost' experience. That is, the landscape supported exploration to the point of losing 




Figure 1 Close up view of installed system.

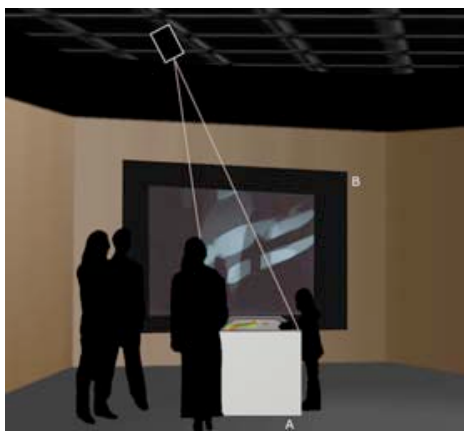

Figure 2 Perspective view of the +-now installation.
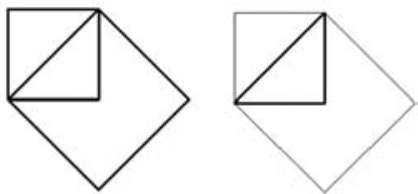

Figure 3 A triangle shape can be seen to emerge from two overlapping squares.

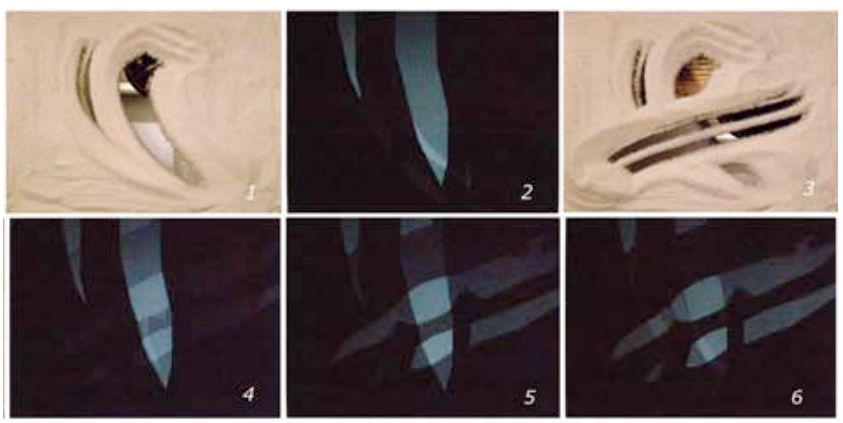

Figure 4 Emergent square shapes can be interpreted in frame 5. These result from overlapping gestures in the sand (frames 1 and 3).



Figure 5 Left and right emergent shapes pulsate to evoke a beating heart, as interpreted by a participant. oneself in one's surroundings. Landscape studies were pursued in an attempt to understand how such an experience can be recreated. They revealed an abundance of visual forms, textures and experiences. This infinite 'richness' characterises all natural landscapes. The natural world is constantly changing and unpredictable. It supports multiple interpretations. For example a pond can be a place for play, quiet reflection, water storage or a habitat for wildlife. In short, the natural world is 'open'.

The art system set out to re-create the experience of being 'lost' in what you are doing. A rich environment supports exploration to this point of losing oneself. Creating an open system subsequently became a design objective.

\section{Emergence in the art system}

Emergence occurs when a new form or concept appears that was not directly implied by the context from which it arose. The triangles in figure 3 are instances of emergent shapes. New shapes can also emerge during interaction with the art system +-now. Persistence of the imagery (its 'echo') means the images of several gestures can overlap. Since the imagery is transparent, overlapping areas accumulate opacity and have greater brightness. The brighter areas can be perceived as emergent shapes (figure 4). Seevinck et al. (2008) discuss this process.

\section{EMERGENCE AND OPENNESS}

Ambiguity of design can translate into a rich experience. Where there is potential for multiple interpretations there may also be depth and variety of experience. Emergence comes about through interpretation and in so doing facilitates openness. The interpretation of emergent shapes in +-now characterizes this as an open system. For example the participant's interpretation of the system image in figure 5 as a 'beating heart'. This occurred during a preliminary case study of participant interaction with +-now. The shape was not deliberately constructed by the participant, rather it was inferred during her interaction with the work (Seevinck et al. 2008).

Architect William Mitchell describes the central role of emergent shapes in creative design. He characterizes the process as ambiguous and with multiple interpretations (Mitchell 1990). These descriptors of emergence can also be applied to openness.

In the domain of computer game design, openness can be facilitated by the inexhaustibility of an emergent structure. Juul (2002) classifies computer games as either progressive or emergent. The former correlates to closed systems and the latter to open systems. The progressive game is closed because as the player progresses through the game each challenge that is presented is completed with their options and solutions explicitly defined. The computer game with a low replay value is typically progressive and closed because it is often exhausted during play, with nothing left to engage the player. Conversely a computer game with a high replay value is typically emergent and open because of the abundance of potential games that can manifest at each playful encounter. For Juul, emergence implies the ability for strategies to surface and for the game-space to extend 
beyond the rules. For example, bluffing during the game of poker. This is another form of emergence to the perceptual emergence in +-now that is discussed above. Both emergent strategies and shapes are unpredictably new structures that appear out of the preceding conditions. However in +-now new shapes are visually interpreted. Using emergence in this way to create openness is unprecedented.

Though not all open works are emergent, all emergence is open. Emergence literature offers a wealth of mechanisms for affording openness in design. This is true of all the approaches to emergence across disciplines (design, gaming, computer science, physics, etc.). Seevinck et al. (2008) classify these approaches to emergence and provide examples from the various domains. Theories of emergence can be very useful where designing for openness, especially considering the limited support for openness in $\mathrm{HCI}$ design.

\section{OPEN DESIGN CONSIDERATIONS}

The natural world may be open but most interactions are designed as closed systems; with clear, singular interpretations and functions. Sengers et al. (2006) explain that interaction design aims to maximise productivity and efficiency. However, by prioritizing clarity of purpose and a single interpretation over uncertainty and ambiguity, openness is excluded. They also argue that openness should be a part of the HCI design language They discuss some examples of open interactive designs and illuminate a range of interpretive mechanisms that are possible between user and system. (see also Gaver et al. 2000; Gaver et al. 2003). As described above, Juul considers openness achieved in emergent games.

Unfortunately there is little other research to inform our understanding of open interaction design. Manovich (2001) describes new media in terms of two forms narrative and database. Narrative is typically linear and causal and as a result pre-determined rather than ambiguous; while the database construction is concerned with specific objects and typically understood as finite rather than inexhaustible. While each of these forms may exhibit degrees of openness they do not contribute to an understanding of what openness is or how to design for it. A similar difficulty exists with Richard Coyne's two approaches to virtual environment design (Coyne 1997). These are the data-oriented approach and the constructivist approach. The former, prevalent method relies on large amounts of data to model a photorealistic, perspective-based version of reality. This is a single, characteristically Western view of the world. While the constructivist method (drawing on perception theorist Gibson) considers reality as an active construction between a viewer and the world, the data-oriented perspective considers only this one model. The dataoriented method does not support multiple interpretations such as those of different cultures. Through its emphasis on perception the constructivist approach acknowledges the role interpretation plays. As such it provides a home for the discussion of openness but does not assist in our understanding of it.
The OZCHI conference theme is timely because a greater understanding of openness is becoming increasingly relevant to the HCI community. Following are some practitioner reflections on characteristics of openness. These emerged during reflection upon, and the creation of, +-now.

\section{Characteristics of open design}

Openness necessitates some creative action or interpretation in the user. Other aspects of openness include unpredictability and increased participant responsibility for the work. This can lead to confusion on the part of the user, particularly since open design differs from the prevalent HCI design models and may run counter to user expectations. Evaluation studies as well as some design methods may assist in successfully creating open systems. The remainder of this section discusses these characteristics of open design. It includes some difficulties and suggests methods for dealing with them.

\section{Creativity}

Interaction with an open system places the participant in a creative role. Whether interpreting the performance of a score; the meaning of emergent shapes during creative interaction with an artwork or creative design; or deciding which strain of artificial life form will reproduce - the audience of an open work plays a larger role than that of the more defined, closed work. Interacting with an open work necessitates making creative decisions. Interacting with the emergent art system +-now has resulted in the interpretation of temporal compositions. The beating heart composition in figure 5 is an example of this.

\section{Unpredictability}

Unpredictability accompanies increased openness. The work is open to the interpretation of the performer for its completion; the artist has ceded some creative control; and as a result there are aspects of the final performance that cannot be predicted (Eco 1962). But unpredictability and increased responsibility do not have to mean a negative experience for the participant. Feedback and structural transparency are two methods that can address unpredictability and increased participant control. They are not unfamiliar to HCI design (e.g. Bowman et al. 2001; Norman 2002). They also emerged during the creation of +-now. This perspective provides specific insight into how they apply to an open work.

Feedback works by confirming to users that their input is registering with the system. For example, in +-now the colourful, augmented, sand surface provides immediate feedback that gestures in the sand have registered successfully. This confirmation is valuable as there is a delay until the layered images on the large screen build up enough for emergent shapes to become visible.

Structural transparency works by establishing a causal relationship between the participant and system. For example, in the installation artwork Homographies, artist Lozano-Hemmer includes a representation of the tracking system (Lozano-Hemmer 2006). This provides the participant with insight into how their movements are affecting the work. Homographies also features 
intermittent 'interludes' where the moving fluorescent tubes briefly cease being influenced by people to instead run through a series of pre-set arrangements. This ordered choreography further communicates the system's potential for order to the participants. In combination with the tracking information, it provides the public with the means to infer a relationship between their action and the system. By facilitating an understanding of the underlying structures a sense of predictability is afforded to the participant. In +-now the process by which the emergent shapes are created is clearly presented. The transparent layers of imagery that add together over time and result in opaque, emergent shapes are easily observed to follow each gesture in the sand.

Providing a user with a cognitive model allows them to frame their interaction and interpretation of the system. This can be achieved by making the structure of the work obvious and providing feedback during interaction so that a cognitive model can be inferred.

\section{Responsibility}

The participant or performer has a greater role to play in the completion of the open work. The responsibility for the work is therefore shared by them. Sengers et al. (2006) consider participant responsibility to increase as the range of interpretations increases, since the artist has relinquished control to them and it is the participant who is creating and completing the work. However, the artist or designer still creates the conditions within which the participant operates; by designing the bounds for interaction possibilities. These issues indicate a need for evaluation studies.

\section{Evaluation}

Evaluation of participant experience is helpful for interaction firstly to determine how the response generated relates to the design objectives. Unexpected responses, like new interpretations, may still be valuable and should not necessarily be rejected. New evaluation criteria may also need to be developed. Sengers et al. (2006) argue that when evaluating open designs one cannot focus on whether a single interpretation was generated but should instead be asking questions like 'how many interpretations were generated?' As this paper has shown, creativity is a characteristic of the open system. It may also be a useful evaluation criterion.

The art system +-now has been evaluated in a single case study (Seevinck et al. 2008). A large evaluation study has also been conducted and is currently being analysed. Preliminary results confirm the 2008 findings, including those discussed in figure 5. That is, a range of interpretations and creative behaviours have been observed during participant interaction with the work.

\section{CONCLUSIONS}

Openness in interaction design mimics the natural world. It also alters the participant's role from a user to a collaborator, increasing both their opportunity for creative collaboration and their responsibility for the work and its form. However, little research into openness currently exists. The broad body of emergence research can help. It can provide methods and insights into the creation of open environments and behaviours. The interactive art system +-now is an example of how openness can be facilitated through emergence based on perception. This is a new research effort. Reflections on the creation of this system include creativity and unpredictability. The discussion of these issues and how they relate to +-now is hoped to be helpful to other artists and designers interested in openness.

\section{REFERENCES}

Azuma, R. T. (1997). A survey of augmented reality. Presence: Teleoperators \& Virtual Environments 6(4): 355-385.

Bowman, D. A., E. Kruijff, et al. (2001). An Introduction to 3D User Interface Design. Presence: Teleoperators \& Virtual Environments 10(1): 96-108.

Coyne, R. (1997). Designing Information Technology in the Postmodern Age From Method to Metaphor. Cambridge, Massachusetts, MIT Press.

Eco, U. (1962). The Poetics of the Open Work. Participation C. Bishop. London, Whitechapel; The MIT Press: $20-40$.

Gaver, B. and H. Martin (2000). Alternatives Exploring Information Appliances through Conceptual Design Proposals. CHI 2000 209-216.

Gaver, W., J. Beaver, et al. (2003). Ambiguity as a Resource for Design. CHI 2003, ACM 233 - 240

Ishii, H. and B. Ullmer (1997). Tangible bits: towards seamless interfaces between people, bits and atoms. Proc. SIGCHI Human Factors, ACM Press 234-241

Juul, J. (2002). The Open and the Closed: Games of Emergence and Games of Progression. Computer Game and Digital Cultures Conference Proceedings, Tampere University Press 323-329.

Juul, J. (2007). Without a Goal. Videogame/Player/Text. T. Krzywinska and B. Atkins. Manchester, Manchester University Press.

Lozano-Hemmer, R. (2006). Homographies Subsculpture 7. Sydney, Interactive art installation

Manovich, L. (2001). The Language of New Media. Cambridge, The MIT Press.

Mitchell, W. J. (1990). A Computational View of Design Creativity. Modeling Creativity and Knowledge-based Creative Design. J. S. Gero and M. L. Maher: 25-42.

Norman, D. A. (2002). The Design of Everyday Things. New York, Basic Books.

Seevinck, J. (2008). +-now. Sydney.

Seevinck, J. and E. Edmonds (2008). Emergence and the art system 'plus minus now'. Design Studies 29(Interaction Design Special Issue): 541-555.

Sengers, P. and B. Gaver (2006). Staying Open to Interpretation: Engaging in Multiple Meanings in Design and Evaluation. Designing Interactive Systems DIS'06, ACM Press 99-108. 


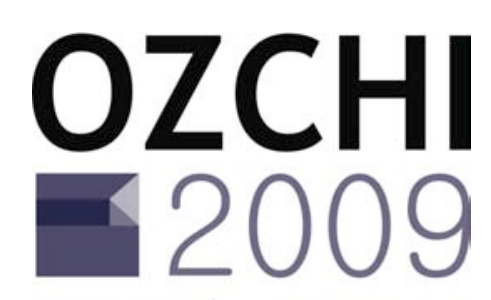

DESIGN | OPEN 24_7

OZCHI 2009, November 23-27, 2009, Melbourne, Australia.

Edited by Jesper Kjeldskov, Jeni Paay and Stephen Viller

Copyright the author(s) and CHISIG

Additional copies are available at the ACM Digital Library (http://portal.acm.org/dl.cfm)

or can be ordered from the CHISIG secretary (secretary@chisig.org)

ISBN: 978-1-60558-854-4 


\section{review process}

The OZCHI 2009 conference held in Melbourne, Australia 23-27 November 2009 received 60 long paper and 88 short paper submissions. From these submissions, 32 long and 42 short papers were selected to appear at the conference. All submitted long and short papers were subjected to double-blind peer review by an independent international reviewing committee of 131 people. Long and short papers were reviewed in their entirety by at least three peers. Industry case studies, panels, and workshop and tutorial proposals were reviewed by their respective co-chairs.

The OZCHI 2009 Proceedings is published by CHISIG and will be available from the ACM digital library shortly after the conference (http://portal.acm.org/dl.cfm). Additional copies can also be ordered from the CHISIG secretary (secretary@chisig.org)

\section{Conference and proceedings details}

The 21st Annual Conference of the Australian Computer-Human Interaction Special Interest Group, OZCHI 2009, 23-27 November 2009, Melbourne, Australia

Proceedings of OZCHI 2009 - Design: Open 24/7

Edited by Jesper Kjeldskov, Jeni Paay and Stephen Viller

Published by CHISIG, Melbourne, Australia (2009)

ISBN no 978-1-60558-854-4

\section{reviewers}

Alexander De Luca

Alexia Fry

Andreea Niculescu

Andrew Dekker

Andrew Vande Moere

Baki Kocaballi

Barney Dalgarno

Ben Kraal

Benjamin Close

Bernd Ploderer

Beryl Plimmer

Bharat Dave

Brendan Ryder

Bruce Thomas

Chao-Lung Lee

Christine Satchell

Christopher Lueg

Clint Heyer

Connor Graham

Daniel Salber

Danielle Wilde

Daryl Ku

David Ahlstrøm

David Jones

David Nichols

Dean Hargreaves

Dharani Perera-Schulz

Dimitrios Raptis

Duncan Stevenson

Elizabeth Kemp

Erik Champion

Flora Dilys Salim

Frank Maguire
Frank Vetere

Fraser Anderson

Gavin Sade

Gerry Gaffney

Gloria Gomez

Greg Wadley

Gregor McEwan

Guillaume Gibert

Hanif Baharin

Harald Holone

Hilal Al Maqbali

Hilary Davis

Holger Regenbrecht

Huanglingzi Liu

Hugh Macdonald

Hyewon Kim

Jan Seeburger

Jan Stage

Jane Li

Janne Jul Jensen

Jason Yang

Jeremy Yuille

Jeni Paay

Jesper Kjeldskov

Jo Vermeulen

John Grundy

John Murphy

Jolynna Sinanan

Jon Pearce

Jonas Fritsch

Julie Maitland

Kari-Jouko Räihä

Kasper Hornbæk
Kasper Løvborg Jensen

Keith Cheverst

Kenton O'Hara

Kim Halskov

Konstantinos Kazakos

Leila Alem

Lejla Vrazalic

Lian Loke

Linda Leung

Lorna Macdonald

Luc Julia

Marcus Foth

Margot Brereton

Maria Hakansson

Marianella Chamorro

Mark Billinghurst

Mark Gaved

Mark Rouncefield

Mark Toleman

Martin Brynskov

Martin Tomitsch

Masood Masoodian

Matthew Willis

Michael Pilling

Michelle Annett

Mikael B. Skov

Mike Broughton

Naisan Yazdani

Natalie Ebenreuter

Natasha Dwyer

Nick Taylor

Nilanthi Seneviratne

Nilma Perera
Pat Lehane

Patrick Watson

Penny Hagen

Peter Dalsgaard

Peter Jones

Ralf Muhlberger

Rene Hexel

Ricky Robinson

Rob Saunders

Ron van Schyndel

Saila Ovaska

Sandrine Balbo

Shawn Ashkanasy

Shiu Wen Wang

Silvia Fajardo-Flores

Sisira Adikari

Siu Man Carrie Lui

Sonja Pedell

Stefan Cronholm

Stefan Schutt

Steve Dillon

Supriya Singh

Susanne Tak

Syariffanor Hisham

Tek Yong Lim

Toni Robertson

Tuck Leong

Vesna Popovic

Victor Gonzalez

Vivienne Farrell

Wendy Hui

Yann Riche 